\title{
Cooling Temperature Control System for the Cross Section Polisher
}

Shogo Kataoka ${ }^{1}$, Munehiro Kozuka ${ }^{1}$, Tsuyoshi Wakasa ${ }^{2}$, Koji Todoroki ${ }^{1}$, Toru Kasai ${ }^{1}$, Tsutomu Negishi $^{1}$, Mituhide Matusita ${ }^{1}$, Hideo Nisioka ${ }^{1}$, Toshiaki Suzuki ${ }^{1}$, and Natasha Erdman ${ }^{3}$

1. IB Business Unit, JEOL Ltd., 3-1-2 Musashino, Akishima, Tokyo 196-8558 JAPAN

2. SASM Design, JEOL Ltd., 3-1-2 Musashino, Akishima, Tokyo 196-8558 JAPAN

3. JEOL USA, Inc., 11 Dearborn Road, Peabody, MA 01960, USA

The Cross Section Polisher (CP) is the instrument to prepare a cross section of a specimen using broad Ar ion beam irradiation with the shielding plate. In the traditional mechanical polishing, experienced skill is required in order to reduce mechanical strain. On the contrary, the CP realized easy preparation of high quality cross sections of specimens without mechanical strain. However, heat-sensitive specimens are easily broken during ion beam irradiation using CP, because ion beam gives heat to the specimen. Then, we had developed a specimen cooling mechanism for the CP using Liquid Nitrogen $\left(\mathrm{LN}_{2}\right)$ cooling, but specimen damage such as interface peeling sometimes happened, especially for low glass-transition temperature (Tg) materials such as adhesive bond and molding material, due to excess cooling by $\mathrm{LN}_{2}$. To solve this problem, we have developed temperature control system for the cooling $\mathrm{CP}$ to prevent excess cooling. In this presentation, we report an effectiveness of this system.

Figure 1 shows the temperature of the specimen holder with setting temperature of $-20{ }^{\circ} \mathrm{C}$. In this result, specimen cooling is controlled by the cooling temperature control system and temperature fluctuation is regulated within $\pm 1^{\circ} \mathrm{C}$. Figure 2 shows SEM images for the lead solder cross sections using the cooling temperature controlled CP. Figure 2(a) shows the milling result without specimen cooling. Under this milling condition, voids are generated at boundaries between lead and tin. Figure 2(b), (c) and (d) show milling results with specimen cooling and assigned temperatures are $-20{ }^{\circ} \mathrm{C},-50{ }^{\circ} \mathrm{C}$, and $-84{ }^{\circ} \mathrm{C}$, respectively. Milling at $-20^{\circ} \mathrm{C}$, some voids are generated (Figure 2(b)). Milling at $-50{ }^{\circ} \mathrm{C}$ or less, any voids can't be observed (Figure 2(c, d)). These results suggest that specimen cooling during ion beam milling prevents sample damages, and the cooling temperature control system optimizes the cooling temperature realizing prevention of excess cooling. 


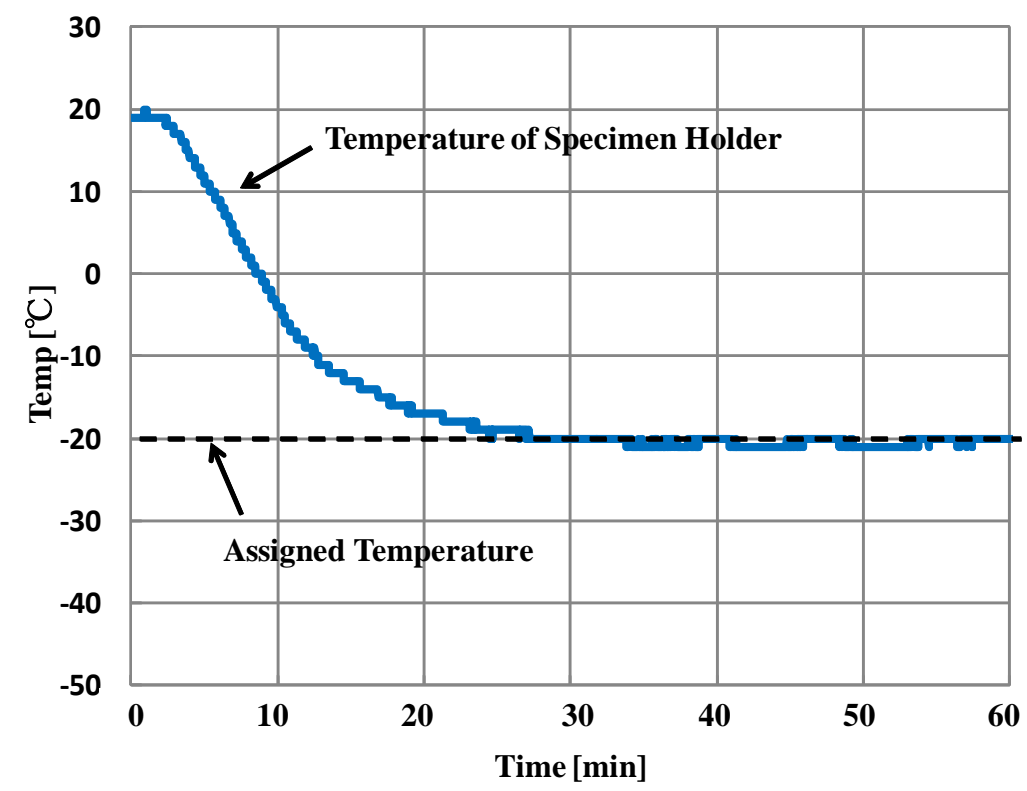

Figure 1. Temperature of the specimen holder using the cooling temperature control system

(a)

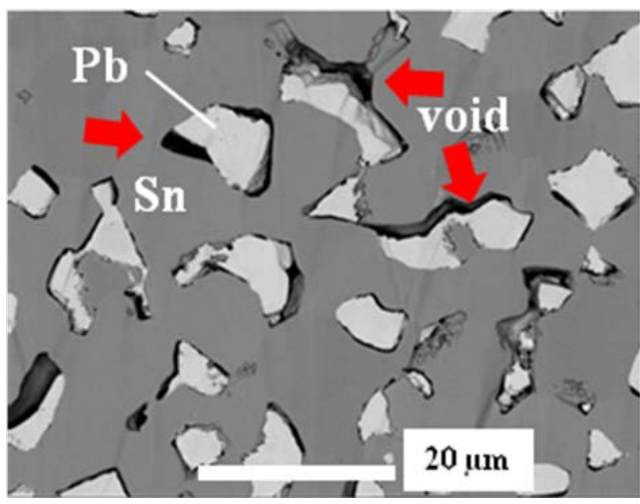

(c)

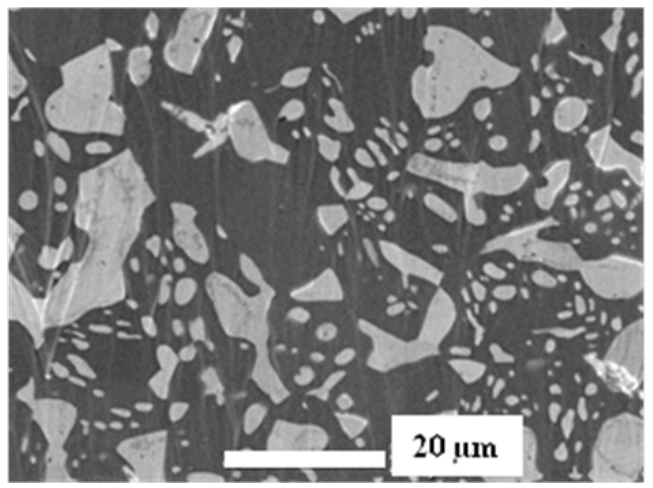

(b)

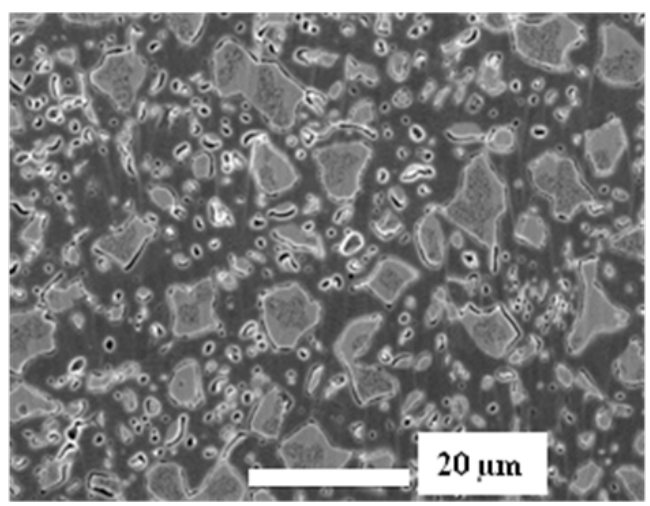

(d)

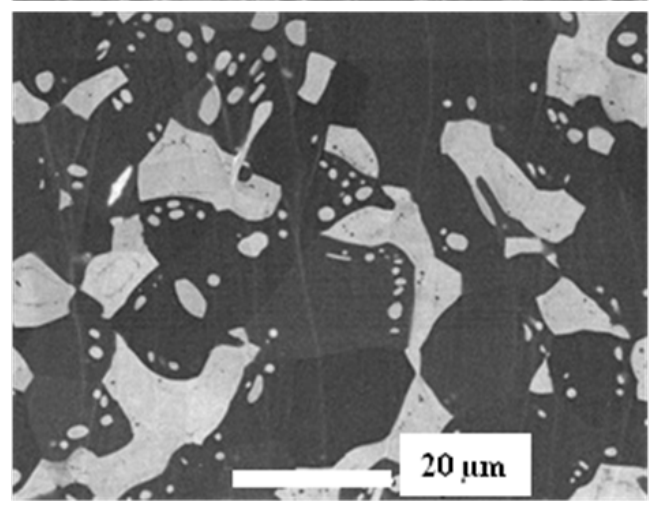

Figure 2. SEM images of cross section specimens of lead solder prepared using the cooling CP. The temperature is regulated by the cooling temperature control system.

(a)Not cooling, (b)Cooling at $-20^{\circ} \mathrm{C}$, (c)Cooling at $-50{ }^{\circ} \mathrm{C}$, (d)Cooling at $-84^{\circ} \mathrm{C}$ 